\title{
Teoria crítica social para leitura crítica da mídia ${ }^{1}$
}

\author{
Critical theory social to critical reading of the media
}

\author{
Teoría crítica social para lectura crítica de los medios \\ José Antônio Ferreira Cirino ${ }^{2}$ \\ Simone Antoniaci Tuzzo ${ }^{3}$ \\ Ana Carolina Rocha Pessôa Temer ${ }^{4}$ \\ http://dx.doi.org/10.5216/33271
}

\begin{abstract}
Resumo
A partir de uma revisão da arte sobre a Escola de Frankfurt e a Teoria Crítica Social, o presente artigo propõe-se a retomar as discussões sobre diversos conceitos e termos frankfurtianos para uma reflexão quanto aos veículos de comunicação e seus produtos informacionais contemporâneos, questionando o papel da mídia nos dias de hoje e seu poder de constituição da realidade. Verificando, inclusive, a continuidade dos construtos críticos na atualidade, através de pesquisadores que se debruçaram na atividade de pensar sobre o sistema comunicacional e seus impactos na sociedade, com uma Leitura Crítica da Mídia.
\end{abstract}

Palavras-chave: Escola de Frankfurt. Teoria Crítica Social. Mídia.

\begin{abstract}
From a review of the literature on the Frankfurt School and Critical Theory Social, this article proposes to resume discussions on various concepts and terms Frankfurtian theories for a reflection regarding the vehicles of communication and its products contemporary informational, questioning the role of the media today and his power of constitution of reality. Analyzing also the continuity of critical constructs in actuality, by researchers who are engaged in the activity of thinking on the communicational system and its impacts on society, with a Critical reading of the Media.
\end{abstract}

Keywords: Frankfurt School. Critical Theory Social. Media.

\section{Resumen}

A partir de una revisión del arte sobre la Escuela de Frankfurt y la Teoría de la Crítica Social, el presente artículo propone retomar las discusiones sobre los diversos conceptos y términos frankfurtianos para una reflexión en cuanto a los vehículos de comunicación y sus propios productos

\footnotetext{
${ }^{1}$ Este trabalho foi desenvolvido dentro do Projeto de Pesquisa Rupturas Metodológicas para uma leitura crítica da Mídia entre os Programas de Pós-Graduação da UFG e UFRJ, que integra a ação transversal no 06/2011 - Casadinho/Procad.

${ }^{2}$ Mestrando em Comunicação na Faculdade de Informação e Comunicação (FIC) da Universidade Federal de Goiás (UFG). Especializando em Gestão de Projetos (IPOG). Graduado em Comunicação Social com habilitação em Publicidade e Propaganda (IESRIVER) e graduado em Gestão de Marketing (UNIP). Brasil, Goiás, Goiânia. E-mail: tonny.mfc@gmail.com

${ }^{3}$ Doutora em Comunicação pela UFRJ, Mestre e Graduada em Comunicação pela UMESP, Docente do PPGCOM da Universidade Federal de Goiás - UFG. Coordenadora do Projeto de Pesquisa Rupturas Metodológicas para uma leitura crítica da Mídia entre os Programas de Pós-Graduação da UFG e UFRJ. Brasil, Goiás, Goiânia. E-mail: simonetuzzo@hotmail.com

${ }^{4}$ Doutora e Mestre em Comunicação Social pela Universidade Metodista de São Paulo, Especialista em Sociologia pela Universidade Federal de Uberlândia e Jornalista graduada na Escola de Comunicação da Universidade Federal do Rio de Janeiro. Coordenadora do Programa de Pós-graduação em Comunicação pela Faculdade de Informação e Comunicação na Universidade Federal de Goiás FIC- UFG. Brasil, Goiás, Goiânia. E-mail: anacarolina.temer@ gmail.com
}

Comun. \& Inf., Goiânia, GO, v. 17, n. 2, p. 155-174, jul./dez. 2014 
informantes contemporáneos, cuestionando el papel de los medios en estos días y su poder de constitución de la realidad. Verificando, inclusive, la continuidad de los constructos críticos en la actualidad, a través de investigadores que han estudiado la actividad de pensar sobre el sistema comunicacional y sus impactos en la sociedad, con una Lectura Crítica de los Medios.

Palabras clave: Escuela de Frankfurt. Teoría de la Crítica Social. Medios.

\section{INTRODUÇÃO}

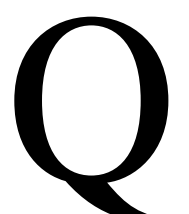

uando da concepção de uma pesquisa em comunicação é imprescindível a escolha teórica e metodológica a qual estará inserida esta produção. Em princípio para nortear o pesquisador e outrora para iluminar os próprios leitores que terão contato com o construto, inserindo-o em um círculo de informações e aspectos teóricos iniciados em outras épocas, dando respaldo e dados comparativos para alicerçar a produção científica em comunicação, assim como nas outras áreas de conhecimento que também se orientam por autores e teorias consolidadas.

Textualmente, Temer e Nery (2009, p. 10-11) trazem a seguinte definição para teorias da comunicação: "conjunto de ideias que buscam entender as ações humanas", além de que "podemos dizer que teoria é a reflexão sobre a prática". Para Polistchuk e Trinta (2003, p. 17) "teoria e prática são indissociáveis; contudo, é possível em algumas circunstâncias e à vista de determinados fins examinar detidamente uma, pressupondo a existência da outra".

Toda prática efetiva carrega consigo uma teoria, um pensamento acerca daquela concepção. A interdependência estabelecida pela filosofia marxista chamada de práxis permeia as pesquisas em comunicação colocando o planejamento e a execução em campos comuns (POLISTCHUK E TRINTA, 2003). Ao tratar das teorias da comunicação entra-se na área que envolve a matéria prima comunicacional (informação), o processo (comunicação) e os resultados a curto, médio e longo prazo da ação (efeitos). Há quem divida os profissionais em teóricos ou práticos, mas de fato se isso realmente existir, ambos cooperam mutuamente para a construção do conhecimento: um contribuindo com os objetos evoluindo as práticas e o outro pensando e refletindo sobre aquelas.

Nesse processo de pensar e refletir sobre as práticas e produtos comunicacionais fazse necessário engendrar dentro de um dos paradigmas (modelos) das teorias da comunicação. Sua escolha não pode ser arbitrária, tendo em vista que determinará todo o enfoque da pesquisa. Vários elementos devem ser levados em consideração, como: qual análise pretende se realizar? Quais as áreas de conhecimento e produção do pesquisador? Que tipo de resultado se espera e quais efeitos se objetiva proporcionar para os estudos da comunicação? E, até 
mesmo, se há afinidade de pensamento entre o pesquisador e os teóricos da corrente escolhida.

Como resposta a estes questionamentos em busca de uma compreensão da leitura crítica da mídia propõe-se uma revisão bibliográfica à luz dos críticos radicais da Escola de Frankfurt. "O Paradigma Crítico Radical está intimamente ligado às reflexões sobre cultura desenvolvidas pela filosofia clássica alemã”, afirmam Temer e Nery $(2009$, p. 85).

\section{ESCOLA DE FRANKFURT}

Os construtos científicos da Escola de Frankfurt foram pioneiros na análise dos meios de comunicação de massa com viés crítico ao sistema capitalista (TEMER E NERY, 2009). Freitag (1990) salienta que o termo Escola de Frankfurt é usado de forma múltipla, ora para designar um grupo de pesquisadores que compuseram o Institut fuer Sozialforschung (Instituto de Pesquisa Social), fundado em 1923, e ora para remeter à Teoria Crítica, principal proposta de análise oriunda deste grupo, afinal a localização geográfica não foi por muitos anos o fator preponderante para unir seus principais autores, tendo em vista que o apogeu das publicações da Escola ocorreu durante a época em que Hitler ascendeu ao poder e considerou o Instituto um inimigo do Estado devido as suas atividades hostis, desativando esta unidade na Universidade de Frankfurt e confiscando os mais de 60 mil livros do acervo. Nomes como Horkheimer, Adorno, Marcuse e Benjamin fizeram parte da essência do movimento e se viram obrigados a se exilar para outras localidades, mas não abandonando sua bandeira acadêmica de produção científica.

Chama-se de Escola de Frankfurt ao coletivo de pensadores e cientistas sociais alemães formado, sobretudo, por Theodor Adorno, Max Horkheimer, Erich Fromm e Herbert Marcuse. Devemos aos dois primeiros a criação de um conceito que se tornou central para os estudos culturais e as análises de mídia: o conceito de indústria cultural. Walter Benjamin e Siegfried Kracauer, embora situando-se na periferia daquele grupo, não são menos importantes, podendo ser contados, junto com os demais, entre os criadores da pesquisa crítica em comunicação. (RÜDIGER, 2007, p. 131)

Provavelmente não havia melhor local e contexto sociocultural para a criação de uma teoria crítica se não o espaço em que se viu dominado pelo maior controlador e ditador já existente (ou pelo menos assim classificado): Adolf Hitler. O nazismo foi o que claramente concedeu a visão pessimista que os frankfurtianos tinham da comunicação, afinal ela foi elemento crucial para a disseminação dos ideais da organização paramilitar Schutzstaffel, ou simplesmente SS. 
Porém os frankfurtianos não se dedicaram a criticar somente o que enxergaram do nazismo, mas, devido ao exílio dos pesquisadores, passaram a ter uma visão de outros lugares do globo para conceberem seus questionamentos reflexivos. Adorno ficou particularmente impressionado ao ir para os Estados Unidos da América e perceber que o controle e coerção exercidos ali eram piores que o do nazismo, pois era auto-imposto, mascarado de ideais libertários que de fato só alienam. Talvez daí surgisse uma das maiores reflexões sobre o sistema ao qual estamos inseridos: não importa quem está no poder, independentemente do partido e de suas ações, o controle e a coerção continuarão existindo, mantendo a supremacia hegemônica.

O instituto era dirigido inicialmente por Carl Guenberg, mas a partir da década de 30 foi substituído por Horkheimer. "O instituto passou a assumir as feições de um verdadeiro centro de pesquisa, preocupado com a análise crítica dos problemas do capitalismo moderno que privilegiava claramente a superestrutura" (FREITAG, 1990, p. 11). O novo diretor havia sido indicado por suas competências e habilidades, e também por sua amizade com Friedrich Pollock e por consequência com Felix Weil, financiador do instituto. "Foi esse financiamento generoso que permitiu ao grupo de intelectuais sobreviver [...], dando ao instituto autonomia e independência que poucos centros de estudos tinham na época” (p. 12).

Como se pode ver facilmente, a primeira fase de existência do Instituto foi decisivamente marcada pela personalidade de Max Horkheimer, sua orientação teórica e suas convicções políticas. Foi ele quem conduziu com firmeza e prudência o processo de institucionalização do Instituto, criando a Revista como porta-voz de seus trabalhos teóricos e empíricos. A ele se deve a maior ênfase no trabalho teórico voltado para a superestrutura, mudando a temática básica do centro de pesquisas por ele administrado. (FREITAG, 1990, p. 15)

Dos pontos constitutivos da Escola que lhe concederam seu ineditismo e abordagem original dos processos de trabalho foi em suma a criação de um novo campo com abordagem filosófica, política e sociológica, abarcando as diversas mazelas e infortúnios nestas áreas com a discussão do cenário daquela época, facilmente aplicável às futuras gerações que vieram pela frente (ASSOUN, 1991).

Rüdiger (2007, p. 132) aponta que "os frankfurtianos trataram de um leque de assuntos que compreendia desde os processos civilizadores modernos e o destino do ser humano na era da técnica até a política, a arte, a música, a literatura e a vida cotidiana”. A partir dessas concepções é que "vieram a descobrir a crescente importância dos fenômenos de mídia e da cultura de mercado na formação do modo de vida contemporâneo” (p. 132). 
Outra situação inerente ao momento das bases frankfurtianas era uma sociedade imóvel e continuamente angustiada, sem rumo e com os seus indivíduos sendo escravizados pelas máquinas e processos técnicos desenvolvidos por eles mesmos e o consumo passa a consumir o consumidor. Os termos mais comuns relacionados a esta escola e os conceitos edificados por seus autores são a Indústria Cultural, a questão da coisificação do homem e os efeitos da reprodutibilidade da arte, discussões que levam a refletir sobre a tecnologia e como ela pode (trans)formar o meio sociocultural dos indivíduos. Por si só "[....] uma postura de análise crítica e uma perspectiva aberta para todos os problemas da cultura do século XX" (TEMER E NERY, 2009, p. 87).

$\mathrm{Na}$ época não foram estudados a TV e tão pouco a internet, mas seus construtos se moldam para uma análise contemporânea e para uma leitura crítica da mídia e das novas mídias. "Nesse contexto os veículos de comunicação passam a ser vistos como meios de dominação e poder, elementos inseridos na indústria cultural e com capacidade de violência simbólica com o receptor [...] O indivíduo deixa de ser sujeito e torna-se objeto.” (TEMER E NERY, 2009, p. 90;93). Com essa afirmação verificamos claramente a posição da Escola de Frankfurt sobre as tecnologias e a (re)produção técnica.

\begin{abstract}
Acabo de sugerir que o conceito de alienação parece tornar-se questionável quando os indivíduos se identificam com a existência que lhes é imposta e têm nela seu próprio desenvolvimento e satisfação. Essa identificação não é uma ilusão, mas uma realidade. Contudo, a realidade constitui uma etapa mais progressiva da alienação. Essa se tornou inteiramente objetiva. O sujeito que é alienado é engolfado por sua existência alienada. Há apenas uma dimensão, que está em toda parte e tem todas as formas. As conquistas do progresso desafiam tanto a condenação como a justificação ideológicas; perante o tribunal dessas conquistas, a falsa consciência de sua racionalidade se torna a verdadeira consciência. (MARCUSE, 1973, p. 31)
\end{abstract}

Essencialmente Rüdiger (2007, p. 138) colabora sobre o conceito mais amplo de Indústria cultural: "Horkheimer, Adorno, Marcuse e outros referiram-se com o termo indústria cultural à conversão da cultura em mercadoria, ao processo de subordinação da consciência à racionalidade capitalista". Mais do que uma crítica à industrialização do processo de trabalho e produção, a critica frankfurtiana à indústria cultural era voltada a castração do pensar, propondo a racionalidade absoluta do capitalismo, o que para os pensadores provocaria a estagnação ideológica da sociedade.

Falar que a TV ou a internet são “ $a$ ” indústria cultural está errado sobremaneira, pois estes são instrumentos e ferramentas para a disseminação dos produtos daquela, mas sendo apenas um dos seus usos. "Noutras palavras, a expressão designa uma prática social, através 
da qual a produção cultural e intelectual passa a ser orientada em fundação de sua possibilidade de consumo no mercado", comenta Rüdiger (2007, p. 138-139), que completa:

[...] a prática da indústria cultural converte-se porém em sistema que a tudo abarca e em que todos os setores se harmonizam reciprocamente. [...] aparecem poderosas empresas multimídia e conglomerados privados, que passam a conferir um poder cada vez maior às tecnologias de reprodução e difusão de bens culturais. [...] Dessa forma, os pensadores do grupo foram os primeiros a ver que, em nosso século, a família e a escola, depois da religião, estão perdendo sua influência socializadora para as empresas de comunicação. $\mathrm{O}$ capitalismo rompeu os limites da economia e penetrou no campo da formação da consciência, convertendo os bens culturais em mercadoria. (RÜDIGER, 2007, p. 138-139)

Erroneamente acreditamos que a indústria cultural pretende mudar gostos ou até mesmo implantá-los na sociedade para que consiga comercializar seus produtos e ideologias, mas não é bem assim. "A prática da indústria cultural segue a linha da menor resistência, não deseja mudar as pessoas: desenvolve-se com base nos mecanismos de oferta e procura, explorando necessidades e predisposições individuais que não são criadas por ela [...]" (RÜDIGER, 2007, p. 143). Esse processo é visto nos estudos de marketing como orientação para o cliente, o qual não produz e vende, mas percebe o que a sociedade quer para que este produto seja naturalmente vendido e não empurrado aos seus desejosos clientes.

Com passos iniciais naquela época, e com sua ascensão atualmente, vemos que as pessoas se tornaram apenas trabalhadores e consumidores, uma ação justificando a outra: trabalha-se para consumir; consome-se para trabalhar; e tantas outras possibilidades.

No contexto da indústria cultural o que ganha visibilidade é somente aquilo que de certa maneira não é pesado para se digerir. A cultura ali transmitida é mastigada várias vezes para chegar aos indivíduos mais simplificada para seu consumo, também com o intuito de não chocar: ela tem que ser aceita pelo maior número de pessoas. Um grande exemplo na cultura brasileira é o funk, antes visto como música de marginais e que só tinha palavras de baixocalão, hoje uma expressão cultural alternativa de diferentes classes sociais e não somente mais do pobre, tendo sido apresentada uma versão mais sutil e que não incomoda, mais voltada ao pop. Esse é um dos vários exemplos que podem ser apresentados, mas este mesmo processo já ocorreu com outros tipos de artes e até mesmo ideologias.

Slater (1978, p. 179) comenta que nos escritos de Adorno havia o destaque para o conceito de pseudo-individualismo, que abarca a crítica à padronização dos produtos e mercadorias distribuídas pela indústria cultural, uma cultura pré-digerida: "e a distribuição dessa mercadoria pseudo-individualizada encontra sua técnica adequada de imposição na 
propaganda, que quebra qualquer resistência ao sempre igual". Atualmente as mercadorias (ideológicas, simbólicas ou materiais) são também evidenciadas empacotadas dentro das matérias jornalísticas, a venda e criação de significados não são mais restritas ao campo da publicidade e propaganda.

Cabe destacar que "[...] a Escola de Frankfurt ataca não é o desenvolvimento da cultura de massas qua (SIC) cultura de massas, mas a forma repressiva específica assumida pela cultura de massa, ou a ela imposta, sob os auspícios do capital monopolista" (SLATER, 1978, p. 177). Os frankfurtianos também se dedicaram a estudar a arte e em alguns escritos a consideram como negação. "A análise da arte [...] parece às vezes ter um tom otimista" (p. 194), tão otimista que a enxerga - sem a máscara da indústria cultural - como algo possuidor de uma aura.

O conceito de aura é esboçado por Benjamim (1990) que considera que as obras primárias e concebidas para a reflexão em um espaço atemporal são raras e que ao serem reproduzidas perdem seu hic et nunc. "Na época de sua reprodutibilidade técnica, o que é atingido na obra de arte é sua aura" (BENJAMIN, 1990, p. 226). Questiona-se se atualmente é possível ainda conceber uma arte pura que tenha aura, visto que tudo já é projetado pensando na sua reprodução e replicação, sem o qual não se consegue ser rentável. $O$ pensador alertou: "as técnicas de reprodução aplicadas à obra de arte modificam a atitude da massa diante da arte", o que pode ser compreendido "à medida que diminui a significação social de uma arte, assiste-se no público a um divórcio crescente entre o espírito crítico e a fruição da obra" (BENJAMIN, 1990, p. 244).

A principal crítica esboçada pelo pensador refere-se às massas buscarem apenas diversão, sendo que para a arte exige-se pensamento, reflexão e dedicação. A diversão é apenas um alivio de tensão. O sistema cansa fisicamente e mentalmente os indivíduos ao ponto de sempre buscarem as práticas mais fáceis para que se possa desligar-se sem preocupação alguma. "A massa é uma matriz de onde brota, atualmente, todo um conjunto de novas atitudes em face da obra de arte. A quantidade tornou-se qualidade" (BENJAMIN, 1990, p. 250).

Freitag (1990) contrapõe explicando que apesar do teor crítico das afirmações de Benjamin ele não foi tão pessimista quanto Adorno sobre a reprodutibilidade das obras de arte, para ele esse processo tratava-se também de politização, dar visibilidade e acesso à cultura. Para Adorno isso não passava de um desvirtuamento da obra, de maneira que ela estaria se diluindo e perdendo a essência em meio às massas.

Comun. \& Inf., Goiânia, GO, v. 17, n. 2, p. 155-174, jul./dez. 2014 
Marcuse (1990) se debruçou a entender a arte na sociedade unidimensional, compreendendo arte num sentido abrangente (música, literatura, "artes figurativas", etc.):

Em muitas das discussões que tive, levantou-se a questão da sobrevivência da arte em nossos tempos. Questionava-se a própria possibilidade da arte, a verdade da arte. Ela era questionada por conta do caráter totalitário de nossa sociedade afluente, que, com facilidade, absorve todas as atividades nãoconformistas e que, em virtude desse mesmo fato, invalida a arte como comunicação e representação de um mundo outro que o do establishment. (MARCUSE, 1990, p.260)

Marcuse (1990) coloca em xeque a possibilidade de vermos arte como arte, devido ao nosso contexto sociopolítico e cultural. E define o papel da arte como o da negação definitiva da realidade, um apelo ao estético pertencente à sensibilidade. "Podemos dizer que a arte descobre e cria uma nova imediação, que emerge apenas com a destruição do velho. [...] Parece-me que a arte como cognição e lembrança depende em grande medida da potência estética do silêncio" (MARCUSE, 1990, p. 264). O silêncio aqui expressado pelo autor referese ao silêncio para a quebra de paradigmas, pois para ele "o ruído é sempre o companheiro da agressão organizada" (p.264). Sua conclusão é que "então a arte, com toda sua força afirmativa, operaria como parte do poder liberador do negativo e ajudaria a libertar o inconsciente e o consciente mutilados [...]" (MARCUSE, 1990, p. 264).

Adorno (2002, p. 45) relembra que "o crítico da cultura não está satisfeito com a cultura, mas deve unicamente a ela esse seu mal-estar. Ele fala como se fosse o representante de uma natureza imaculada ou de um estágio histórico superior, mas é necessariamente da mesma essência daquilo que pensa ter a seus pés".

Todas essas discussões sobre arte libertadora, arte afirmativa, negação, indústria cultural e ademais conceitos, levaram a proposição da Teoria Crítica como bússola norteadora dos frankfurtianos.

\section{TEORIA CRÍTICA SOCIAL}

No momento do exílio dos pensadores frankfurtianos em 1933 o Instituto foi transferido para Genebra, e em 1934 para Nova Iorque, mas ainda mantendo o apoio financeiro que lhe assegurava autonomia. "Neste período de emigração o Instituto concede mais de cinquenta bolsas de estudo e de pesquisa a intelectuais e judeus perseguidos pelo nazismo na Europa" (FREITAG, 1990, p. 16). No período em que o Instituto se encontrava nos EUA teve forte produção acadêmica publicada em sua Revista própria, construtos que culminaram na Teoria Crítica. 
A teoria crítica foi consolidada com esse nome devido a um artigo publicado por Horkheimer na revista científica de pesquisa social Zeitschrift fuer Sozialforschung em 1937 sob o título de Teoria tradicional e Teoria Crítica, construto que reuniu os aspectos principais já trabalhados por todos os autores deste grupo de reflexão social (ASSOUN, 1991).

A teoria crítica trata de esclarecimento e emancipação, como premissa da crítica possui conteúdo cognitivo e se diferenciam das teorias das ciências naturais, por não objetificar, mas sim refletir sobre o objeto estudado. Para Geuss (1988) quando se fala em esclarecer e emancipar uma sociedade trata-se de um tipo de transição social em que se parte de uma situação inicial (status quo) para uma situação pretendida:

a) $\mathrm{O}$ estado inicial apresenta tanta falsa consciência e erro, quanto "existência sem liberdade". b) No estado inicial, falsa consciência e existência sem liberdade estão intimamente ligadas, de modo que os agentes só podem ser libertos de uma situação se eles também forem ao mesmo tempo libertos da outra. c) A "inexistência sem liberdade" de que padecem os agentes no estado inicial é uma forma de coerção auto-imposta; a falsa consciência deles é um tipo de auto-ilusão. d) A coerção de que padecem os agentes no estado inicial é uma coerção cujo "poder" ou "objetividade" deriva-se apenas do fato de que os agentes não percebem que é auto-imposta. e) $\mathrm{O}$ estado final é aquele em que os agentes estão livres da falsa consciência - eles foram esclarecidos - e livres da coerção auto-impostas - eles foram emancipados. (GEUSS, 1988, p. 97)

A emancipação da qual trata o autor à luz dos estudos críticos radicais remete-nos a necessidade de uma libertação da sociedade e uma quebra dos paradigmas atuais no que concerne principalmente ao monopólio de poder de fala, aludido por Lemos e Levy (2010) em sua obra sobre a ciberdemocracia. Todos se lembram de discutir sobre o monopólio do petróleo, das empresas de transporte, etc., mas se esquecem do monopólio mais poderoso que determinam quais serão os próprios monopólios em destaque: o monopólio da fala, da voz.

Vivemos momentos difíceis em que a emancipação ideológica e de fala é uma questão crucial para a evolução dos indivíduos e da própria sociedade. O controle e coerção impostos pelos indivíduos a si próprios ao replicar os discursos e as ações orientadas como as mais adequadas, castram o ideal revolucionário da busca alternativa de soluções. A crítica vem para romper com os próprios modelos metodológicos estabelecidos como padrões dentro da pesquisa.

Teorias críticas são opostas às teorias científicas, pois as científicas exigem confirmações empíricas a partir de experimentos e atividades totalmente positivistas e às críticas se mantém conforme o grau de aceitação de suas reflexões e a viabilidade/validade

Comun. \& Inf., Goiânia, GO, v. 17, n. 2, p. 155-174, jul./dez. 2014 
delas para aplicação no momento vigente. "Uma meta básica da Escola de Frankfurt é a crítica ao positivismo e a reabilitação da reflexão com uma categoria de conhecimento válido" (GEUSS, 1988, p. 9). Além disso, sua condição de teoria social o é outorgado graças a sua preocupação com a sociedade como um todo e detentora de estrutura cognitiva reflexiva. Assim como a teoria Marxista da sociedade que "se propõe a considerar tanto as instituições sociais e econômicas 'objetivas' da sociedade como os principais tipos de convicções que os agentes na sociedade conservam" (GEUSS, 1988, p. 93).

1 - Teorias críticas têm posição especial como guias para a ação humana, visto que: a) elas visam produzir esclarecimento entre os agentes que as defendem, isto é, capacitando esses agentes a estipular quais são seus verdadeiros interesses; b) elas são inerentemente emancipatórias, isto é, elas libertam os agentes de um tipo de coerção que é, pelo menos parcialmente, auto-imposta, a auto-frustração da ação humana consciente. 2 - Teorias críticas têm conteúdo cognitivo, isto é, são formas de conhecimento. 3 Teorias críticas diferem epistemologicamente de teorias em ciências naturais, de maneira essencial. As teorias em ciência natural são "objetificantes"; as teorias críticas são "reflexivas". (GEUSS, 1988, p. 8)

De acordo com Guareschi (1991, p. 54), “as teorias críticas dão um passo atrás e passam a examinar as 'configurações de mundo' que podem ser utilizadas para legitimar instituições sociais repressivas". Na interpretação do autor, "não haveria libertação verdadeira enquanto não houvesse consciência da figuração de mundo ideológica e enquanto essas instituições coercitivas básicas estivessem imunes à livre discussão e à crítica” (p. 54).

Sinteticamente, a teoria crítica prevê uma desalienação ou iluminação dos indivíduos sobre sua característica de controlado para que se possa obter a libertação e outro caminho possível por meio da reflexão. A Escola de Frankfurt não é pessimista para ser pessimista, mas sim tem uma visão crítica da realidade social com o propósito de imaginar uma outra situação possível e não só o que está em vigência. É a prática do pensar fora da caixa, tão difícil nos dias atuais. Talvez por isso seja uma escola de pensamento extremamente criticada, a maioria das pessoas não conseguem se imaginar fora desse sistema e por isso é quase nãocrível ver uma alternativa de sobreviver fora dele.

Com este ângulo, podemos trazer as contribuições contemporâneas e atuais de uma crítica social para analisar os diferentes aspectos da cidadania a partir da ótica dos dominados pelos aparelhos ideológicos do Estado que sofrem diariamente com a execução de um poder simbólico que violenta e agride os (sub)cidadãos, usuários e pedintes das benesses públicas (educação, saúde, segurança, transporte, etc.). Rüdiger (2007, p. 144) conclui que "a reflexão crítica, ao contrário, não tem por objetivo provar alguma tese mas, sim, nos fazer pensar e, por

Comun. \& Inf., Goiânia, GO, v. 17, n. 2, p. 155-174, jul./dez. 2014 
aí, nos tornar mais conscientes ao mesmo tempo dos limites e potenciais de mudança existentes na realidade".

Um dos preceitos explicitados por Nobre (2008, p. 22) é que "nos escritos de Horkheimer da década de 1930, o campo da Teoria Crítica tem como critério de demarcação fundamental o seguinte: produz Teoria Crítica todo aquele que desenvolve seu trabalho teórico a partir da obra de Marx". Apesar de ser baseada nas obras marxistas, o próprio autor relata que uma das premissas da teoria crítica (TC) também é de ser dinâmica e em constante mutação. "O marxismo não intervém na problemática frankfurtiana como uma doutrina exterior: é a principal referência teórica que legitima a Teoria Crítica" (ASSOUN, 1991, p. $56)$.

Isso dificulta a teorizar sobre a TC, mas ao mesmo tempo lhe fornece um caminho de possibilidades para atualizar-se para a sociedade midiática a qual estamos inseridos, talvez seja exatamente sua essência flexível e múltipla que lhe fez perdurar nos dias de hoje e ainda conseguir ter aplicabilidade. A sociedade mudou, temos novas tecnologias e formatos de relacionamento, tanto das pessoas com pessoas, empresas com pessoas, pessoas e o meio ambiente, e vice-versa. Mas o que nunca mudou são os problemas: os eternos conflitos entre hegemonia e contra-hegemonia (ou dominador e dominados); a falta de educação, saúde, transporte, etc., por parte do governo para os (sub)cidadãos ainda são os mesmos; a demanda não pára de crescer, tampouco as exigências. A TC se adapta facilmente a esse cenário: sempre onde houver pessoas controladas e coagidas haverá a possibilidade de se criticar e refletir sobre estes processos buscando uma emancipação.

Por isso, a tarefa primordial da Teoria Crítica desde sua primeira formulação na obra de Marx é a de compreender a natureza do mercado capitalista. Compreender como se estrutura o mercado e de que maneira o conjunto da sociedade se organiza a partir dessa estrutura significa, simultaneamente, compreender como se distribui o poder político e a riqueza, qual a forma do Estado, que papéis desempenham a família e a religião, e muitas outras coisas mais. Diferentemente de todas as formas históricas anteriores, no capitalismo todo e qualquer artefato é um produto para ser trocado. É a lógica da troca que determina o comportamento dos agentes no mercado, e não quaisquer ou as motivações como valores, crenças religiosas ou determinações culturais. Não se pretende com isso dizer que não haja valores e crenças, mas sim que, no mercado, eles devem se subordinar à lógica da troca mercantil. A fim de compreendê-la, é preciso começar a análise por sua unidade elementar, a mercadoria. Dizer que o mercado é o centro em torno do qual se organiza o conjunto da sociedade capitalista significa então dizer que, potencialmente, todo e qualquer bem deve ter um determinado valor, quer dizer, que todo bem deve poder ser apreciável, deve poder assumir a forma de uma mercadoria. (NOBRE, 2008, p. 25-26) 
Partindo disso temos em mente a principal matéria-prima dos estudos e pesquisas da TC: o capitalismo. Pode parecer um discurso socialista/comunista, mas não precisa ser contrário ao sistema capitalista para ver que ele é falho em várias áreas e que se faz necessário reavaliar como podemos melhorá-lo, principalmente na parte dos direitos sociais aos cidadãos que ainda são um longo caminho a percorrer. Não é ser contra, ao invés disso é ser a favor da evolução e da melhoria. Houve a abolição da escravatura, mas se instituiu um novo tipo de escravidão: simbólica e monetária. Como se emancipar de uma dominação auto-imposta e que é o único caminho visível dentro da sociedade?

Ademais a função de troca do sistema capitalista, outra questão discutida pelos críticos e pensadores com as bases marxistas refere-se ao aprofundamento das desigualdades, característica essencial do capitalismo que por consequência de suas ações provoca o aumento da riqueza por um lado, e do outro aumenta a pobreza (NOBRE, 2008). Ao se inspirar nos estudos críticos, a reflexão quanto à divisão de classes é imprescindível, pois justifica toda a problemática nas relações entre Estado e indivíduos.

A análise crítica dos poderios simbólicos que representam todos os discursos impostos à sociedade pelo monopólio do poder de fala é a possibilidade de revelar e promover a real libertação proposta por Marx. Outrora essas ações poderiam ser consideradas utópicas, mas o fato de não conseguir destruir todo o sistema não quer dizer que não tenha contribuído de alguma maneira para que ele faleça a cada dia. A TC vem nesta perspectiva de minar as formas ocultas de coerção para a busca da liberdade, se assim podemos chamar esta condição de soltura das amarras capitalistas.

Os princípios fundamentais da TC, expostos por Nobre (2008), são: a orientação para emancipação e o comportamento crítico. Esses dois concedem alicerce para uma análise aprofundada do objeto estudado, optando por demonstrar mais do que a revelação simplificada da dominação, mas desvendá-la e oferecer aos dominados as raízes dessa coerção para que consigam se desvencilhar, caso consigam.

Outra doutrina forte, raiz da TC, é evidenciada por ASSOUN (1991, p. 74): “a psicanálise intervém na Teoria Crítica como um instrumento, que em determinado momento ela tem de usar [...] Isso significa igualmente que a psicanálise é inserida numa teoria do social". Para os pensadores da Escola de Frankfurt, Freud foi uma de suas leituras primordiais, catalogando-os como freudo-marxistas.

Em 1950, após o retorno de Adorno do seu exílio imerso em todo sofrimento e negatividade ocasionados pelo holocausto, ele desenvolveu a Teoria Estética. Esta não se 
tratou de uma ruptura com a teoria crítica, mas um aprofundamento exploratório radical com uma ênfase específica à estética, longe da visão sociológica (FREITAG, 1990), por isso esta teoria não é foco deste trabalho.

No Brasil, a teoria crítica foi recebida na década de 60 para 70, momento mais opressivo e dominador da política em solo brasileiro, a fase negra da ditadura militar. Com isso verificamos que em meio à repressão sempre surge a necessidade da crítica. Quando a população e seus pensadores se sentem reprimidos de alguma maneira, ali nasce a reflexão crítica e o desejo de emancipação.

Não há dúvida de que o pensamento crítico da Escola de Frankfurt permanece mais vivo, virulento e polêmico como nunca, o que supõe fidelidade às origens, mas também renovação. [...] é possível dizer que têm em comum um compromisso inquebrantável com a emancipação, apesar da solidez do mundo unidimensional [...] Frankfurt passou a ser uma referência simbólica, e não um lugar geográfico. (FREITAG, 1990, p. 149;151)

Os herdeiros brasileiros da reflexão crítica no Brasil são Paulo Freire e José Marques de Melo que servem de referência e inspiração para a condução de diversos produtos científicos na área da comunicação brasileira até os dias de hoje. Outro ponto trabalhado por estes autores e da corrente que foi chamada Escola Latino-Americana é sua crítica às construções sobre opinião pública, que para eles são um discurso da classe hegemônica e uma estratégia para manter o consenso.

Esse sentimento de propor o dissenso, ou a própria falta de senso, para uma mutiplicidade de vozes e uma real democracia, seria o primeiro ponto em comum e uma possível continuidade da Teoria Crítica dentro do Brasil, pois ambos enxergam os meios de comunicação como uma forma de exercer influência e controle à população, necessitando um pensamento crítico em relação aos produtos e aos produtores para que se consiga refletir sobre isso e entender as práticas sociais envoltas no processo. $\mathrm{O}$ segundo ponto é a visão do materialismo histórico e o próprio marxismo implícito e explícito em diversas obras de ambas as correntes.

A aceitação da perspectiva frankfurtiana no campo da comunicação no Brasil passou por diversos períodos. Após uma primeira fase de descoberta e incorporação desses teóricos nos anos 1970, os mesmos foram sendo relegados a segundo plano, recebendo inclusive a alcunha de apocalípticos. Posteriormente, na década de 1980 - tendo como ponto de referência a obra de Adorno -, seriam tachados de pessimistas, e a crítica à indústria cultural, esvaziada de seu conteúdo. [...] A partir de uma revisão bibliográfica, vimos alguns dos pontos mais polêmicos que cercam a dialética do esclarecimento e as críticas em relação à indústria cultural, especialmente na visão de dois autores, Umberto Eco e Jesus Martín-Barbero, um com um olhar europeu e o 
outro com uma visão latino-americana. Ao pensarmos o legado da Escola de Frankfurt, é interessante sempre retomar o ponto de partida dos próprios teóricos, seu contexto social e histórico, para entender como é possível que, prestes a completar 90 anos da inauguração do Instituto de Pesquisas Sociais, seus textos continuem sendo estudados com tanta atenção. (MOGENDORFF, 2012, p. 159)

O legado frankfurtiano se prova como uma alternativa real de busca da emancipação através da reflexão crítica. Em um mundo cada vez mais positivista e funcionalista em que tudo se tem um preço, uma função e um por que, fica difícil imaginar uma teorização crítica, mas não impossível. Um dos pontos essenciais para a discussão dos caminhos futuros é o papel do poder simbólico exercido pela mídia e como ele sustenta todo o sistema capitalista. “A mediação entre o Estado (o capital) e os trabalhadores é, agora, feita pela 'comunicação', que controla essa tarefa com afinco" (GUARESCHI, 1991, p. 64). Todo pesquisador que se preocupe com as questões socioculturais deve se dedicar a entender o que é divulgado pelos veículos de comunicação e promover uma leitura crítica de seus produtos para entender a relação Estado versus o povo.

\section{LEITURA CRÍTICA DA MÍDIA}

Talvez a maior das críticas aos meios de comunicação não seria o fato da divulgação de produtos e ideologias para o controle social, embora sejam muito criticadas por isso, mas sim ao fato da transmissão de entretenimento e ocupação que calam o silêncio tão necessário e defendido pelos frankfurtianos. Ao preencher todo o silêncio e vazio do espaço de tempo dos indivíduos, a mídia proíbe que ele possa e consiga pensar sobre outros assuntos que não estão ali mencionados. Esse é outro ponto: a mídia ao pautar futilidades, sensacionalismos e inutilidades não está errada, pois está em seu direito de liberdade de expressão, embora não esteja certa. Ao priorizar alguns assuntos isso está sendo feito em detrimento de outros que não estão sendo veiculados. O não dizer também é uma forma de dizer: deixa-se claro que não pode se pensar sobre isso ou aquilo. Ao mostrar entretenimento foge à sua obrigação de ser espelho da sociedade, de veicular os fatos e informar os ouvintes/telespectadores/leitores.

As comunicações são importantes não porque veiculem ideologias, mas sim porque, se de um lado fornecem as informações que colaboram para seu esclarecimento, de outra proporcionam entretenimento que elas procuram com avidez e sem o qual talvez não pudessem suportar o crescente desencantamento da existência. [...] Também neste aspecto, porém, conviria observar que o principal não está no conteúdo dos meios mas no fato de as pessoas estarem a eles ligados como bens de consumo. [...] A programação transmitida, muitas vezes avaliada criticamente, é bem menos importante do

Comun. \& Inf., Goiânia, GO, v. 17, n. 2, p. 155-174, jul./dez. 2014

Caderno Casadinho Procad UFG - UFRJ 
que suas funções de preencher um ambiente, matar o vazio ou entreter o indivíduo com o equipamento. (RÜDIGER, 2007, p. 142-143)

Temer e Nery $(2009$, p. 89) avaliam que "o acesso à informação, que deveria ser o instrumento da modernidade para libertar a consciência humana do medo, [...] não apenas deixa de cumprir essa missão, como se torna ela própria um instrumento de dominação".

Para compreender esses processos midiáticos de superexposição de determinados assuntos e ocultação de outros, além da clara distribuição de pacotes ideológicos nas entrelinhas das matérias/textos, valemo-nos da reinterpretação sobre a mídia. A leitura crítica destes processos.

A proposta de reinterpretação consiste na revisão teórica e metodológica do histórico processo de Leitura Crítica da Comunicação, desde sua implementação nos anos 1970. [...] Nesta proposta de pesquisa, portanto, o ponto de partida é o entendimento da crítica como possibilidade de redescobrir - o lançar um novo olhar - mais profundo, que permita desconstruir a realidade e a partir daí lance bases para propostas de transformação. (TUZZO, 2014, p. 160)

De acordo com Paiva e Gabbay (2009, p. 10) “no Brasil e mesmo na América Latina a referência básica sobre a proposta da Leitura Crítica da Comunicação tem sempre se referenciado na atuação da União Cristã Brasileira de Comunicação Social (UCBC)”.

A UCBC oferecia mini-cursos sobre comunicação em geral para membros da igreja e estudantes secundaristas. Essa atitude se desdobrou em diversas outras ações que culminaram na criação do Projeto de Leitura Crítica da Comunicação, que a partir daí despontou na publicação de diversos materiais voltados à elucidação quanto ao poderio midiático. (PAIVA e GABBAY, 2009)

Portanto, o pensamento e a leitura crítica demandam a preservação da "exterioridade ao puro artifício técnico" dos meios de comunicação e mediação, ou seja, ter "um pé fora do fechamento das redes, mas dentro do empenho vital de geração de valor humano", uma ética presente nas relações com o mundo midiatizado, que remonta à uma nova relação com o lugar, o território cultural. [...] Assim, acreditamos que toda proposta de leitura crítica dos meios de comunicação e dos produtos cultuais no bios midiático deve passar não só pela recuperação da profundidade histórica, mas também por uma reflexão sobre as determinações mercadológicas da produção informacional. Os novos meios oferecem facilidade técnica para a publicação/circulação de informações e, de várias formas, colocam em cheque a própria prática jornalística, na medida em que abrem a possibilidade para a produção de informantes autônomos, amadores e experimentais. No meio dessa avalanche informacional, com notícias e construções (retratos) da realidade que se sobrepõem nas mídias eletrônicas e digitais, o imperativo da crítica faz-se ainda mais necessário. (PAIVA e GABBAY, 2009, p. 8-9) 
Com a exposição do cenário contemporâneo da produção jornalística retratada por Paiva e Gabbay (2009), é possível compreender a necessidade - salientada desde a época do nascimento da Escola de Frankfurt - de preocupar-se com a indústria cultural, os conglomerados midiáticos e mais especificamente com o que tem sido divulgado aos indivíduos. A leitura crítica vem ocupar nas pesquisas brasileiras o espaço e o campo teóricocrítico que elucida e revela o lado humano do rádio, TV, jornais, internet, etc. Humano, pois, assim como os seres que os concebem e controlam, estão passíveis de erros, conscientes ou inconscientes capazes de gerar uma nova visão sobre a realidade, ou constituir uma própria nova realidade.

Não há como não perceber que a indústria cultural, tratando especificamente dos conglomerados midiáticos, transformou também o próprio papel do jornalismo, gerando uma economia da informação (SODRÉ, 2009) que outrora não existia, fazendo com que a notícia seja algo extremamente perigoso nas mãos apenas do jornalista (MARSHALL, 2003), incentivando o desenvolvimento do mercado publicitário e de gerenciamento de comunicação que produz e distribui informações através até dos próprios jornalistas, por um processo silencioso da tentativa de controle da opinião pública. Porém essas foram preocupações dos neo-frankfurtianos, como Habermas.

Difícil não recordar do fato histórico que remonta ao final da década de 30, quando o radialista resolveu fazer uma leitura da ficção científica Guerra dos Mundos gerando um caos na sociedade americana, anos depois repetida no Maranhão gerando o mesmo efeito ${ }^{5}$ : pessoas aguardando a morte no dia do apocalipse alienígena. A confusão ocorreu pela falta do limiar crítico e os limites entre a leitura literária e o rádio-jornalismo da época. Aí vem a questão: será que em pleno século XXI as pessoas já conseguem distinguir realidade da ficção? Distinguir sensacionalismo de exposição dos fatos? Entender o que é narrativa literária ficcional e o que é programa jornalístico?

Se pararmos para refletir nos produtos midiáticos de hoje os gêneros discursivos estão misturados: são novelas com debates de fatos reais; jornais com simulações ficcionais; matérias com opiniões não profissionais e elucubrações mentais que refletem a realidade de visão de uma única pessoa vista como matéria jornalística e divulgada nos principais centros

\footnotetext{
${ }^{5}$ Sobre isso, ler: http://g1.globo.com/pop-arte/noticia/2011/10/programa-de-radio-que-causou-panico-nomaranhao-faz-40-anos.html
} 
de notícia e por aí vão os exemplos. O caos está sendo criado pelos veículos de comunicação, cada qual com sua contribuição, e não estamos percebendo? A nova realidade de mundo está sendo desenhada não pela sua consequência de ações, mas pela visão que temos delas e que se transformam na própria realidade? Que tipo de mundo a mídia está construindo? À que tipo de mundo estamos sendo expostos?

Sodré (2009) debate um deslizamento do texto jornalístico inclinado às narrativas literárias. Esse novo formato de escrever e transmitir a realidade moldada pelos veículos de comunicação somente dificultou o processo de entendimento dos textos/imagens. Como os indivíduos recebem as informações? Eles possuem discernimento suficiente para compreender o que é real e o que real fabricado? Como promover uma emancipação deste poder simbólico se os próprios indivíduos se mantêm neste processo coercitivo e não enxergam a necessidade da libertação?

Assim como as pessoas que ouviram a história da Guerra dos Mundos pelo rádio décadas atrás, nós, a população contemporânea, não estamos acreditando em uma nova guerra dentro do mundo que nos está sendo contada através da mídia? Todas estas reflexões fazem parte dos estudos da teoria crítica social para uma leitura crítica da mídia.

\section{REFERÊNCIAS}

ADORNO, Theodor W. Indústria cultural e sociedade. São Paulo: Paz e Terra, 2002.

ASSOUN, Paul-Laurent. A Escola de Frankfurt. São Paulo, Editora Ática S.A., 1991.

BENJAMIN, Walter. A obra de arte na época da sua reprodutibilidade técnica. In: LIMA, L. C. Teoria da Cultura de Massa. Rio de Janeiro: Paz e Terra, 1990, p. 215-254.

FREITAG, Barbara. A teoria crítica: ontem e hoje. São Paulo: Brasiliense, 1990.

GEUSS, Raymond. Teoria crítica: Habermas e a Escola de Frankfurt. Campinas, São Paulo: Papirus, 1988.

GUARESCHI, Pedrinho A. Comunicação e Teoria Crítica. In: GUARESCHI, P. A. (org.). Comunicação \& Controle Social. Rio de Janeiro: Vozes, 1991. p. 52-71.

LEMOS, André; LEVY, Pierre. O futuro da internet: em direção a uma ciberdemocracia. São Paulo: Paulus, 2010.

MARSHALL, Leandro. O jornalismo na era da publicidade. São Paulo: Summus, 2003.

MARCUSE, Herbert. A ideologia da sociedade industrial: o homem unidimensional. Rio de Janeiro: Zahar, 1973. 
MARCUSE, Herbert. A arte na sociedade unidimensional. In: LIMA, L.C. Teoria da Cultura de Massa. Rio de Janeiro: Paz e Terra, 1990, p. 255-270.

MOGENDORFF, Janine Regina. A Escola de Frankfurt e seu legado. Verso e Reverso, v. 23, n. 63, p. 152-159. 2012.

NOBRE, Marcos. A teoria crítica. Rio de Janeiro: Zahar Editores, 2008.

PAIVA, Raquel; GABBAY, Marcelo. Leitura crítica e cidadania: novas perspectivas. In: CONGRESSO BRASILEIRO DE CIÊNCIAS DA COMUNICAÇÃO, 32., 2009, Curitiba. Anais... Curitiba: Intercom - Sociedade Brasileira de Estudos Interdisciplinares da Comunicação, 2009.

POLISTCHUK, Illana; TRINTA, Aluizio Ramos. Teorias da Comunicação: o pensamento e a prática do jornalismo. Rio de Janeiro: Elsevier, 2003.

RÜDIGER, Francisco. A Escola de Frankfurt. In: Hohlfeldt, A.; Martino, L. C.; França, V. V. (orgs). Teorias da Comunicação: conceitos, escolas e tendencias. 7. ed. Petrópolis, RJ: Vozes, 2007, p. 131150.

TEMER, Ana Carolina Rocha Pessoa; NERY, Vanda Cunha Albieri. Para entender as teorias da comunicação. Uberlândia: EDUFU, 2009.

TUZZO, Simone Antoniaci. O lado sub da cidadania a partir de uma leitura crítica da mídia. In: PAIVA, Raquel; TUZZO, Simone Antoniaci. Comunidade, mídia e cidade: Possibilidades comunitárias na cidade hoje. Goiânia: FIC/UFG, 2014, p. 151-180.

SLATER, Phil. Origem e significado da Escola de Frankfurt. Rio de Janeiro: Zahar Editores, 1978.

SODRÉ, Muniz. A narração do fato. Petrópolis: Vozes, 2009. 